Application note

\title{
A multi-approach software library for estimating crop suitability to environment
}

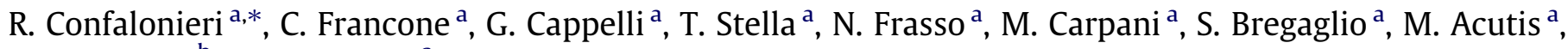 \\ F.N. Tubiello ${ }^{b}$, E. Fernandes ${ }^{c}$
}

${ }^{a}$ University of Milan, Department of Plant Production, CASSANDRA, Via Celoria 2, 20133 Milan, Italy

${ }^{\mathrm{b}}$ Natural Resources Department, FAO, Via Terme di Caracalla, 00153 Rome, Italy

${ }^{\mathrm{c}}$ The World Bank, Agricultural and Rural Development (LCSAR), 1818 H St., NW, Washington, DC 20433, USA

\section{A R T I C L E I N F O}

\section{Article history:}

Received 20 April 2012

Received in revised form 15 September 2012

Accepted 28 September 2012

\section{Keywords:}

Adaptation

Climate change

Agro-ecological zone

Crop suitability

Software components

\begin{abstract}
A B S T R A C T
The assessment of crop biophysical suitability to agro-environmental conditions is a valuable component of crop production studies, especially when evaluating productivity potential of new crops and areas, or for the assessment of potential cultivation shifts and crop adaptation needs under climate change scenarios. The software component Suitability presented herein implements several published approaches for computing crop suitability, based on available climate, soil and crop information. Users can access the Suitability software component via two application programming interfaces for single- and multi-cell estimations, the latter based on multiple regression methods. The component, extensible by third parties, is released as .NET 3.5 DLL, thus targeting the development of .NET clients. A case study on wheat suitability in Morocco is also presented.
\end{abstract}

(c) 2012 Elsevier B.V. All rights reserved.

\section{Introduction}

Evaluating crop suitability - i.e., how agro-environmental conditions control establishment and growth of specific crop species and their cultivars - is a valuable component of agro-ecological assessment studies (e.g., Ceballos-Silva and López-Blanco, 2003), allowing for the assessment of potential productivity of crops under a variety of current or future conditions, including changes to crops geographic distribution under climate change (Hood et al., 2006). Soil type and climatology, in particular local thermo-pluviometric regimes (Jing-Song et al., 2012), determine overall crop productivity; suitability assessments thus help identify production potential under specific conditions, including those associated with different management choices - such as fertilization and irrigation amounts or with a range of projected climate scenarios - which may drive crop cultivation towards higher latitudes (e.g., Jarvis et al., 2008). In this context, different criteria have been proposed for evaluating crop suitability to environmental conditions, ranging from simple approaches based on temperature and precipitation during the growing season (e.g., Woodward, 1987) to complex criteria requiring a variety of information on climate, soil chemistry, soil physics, etc. (e.g., Eliasson et al., 2010).

In particular for climate change applications, most of the available agro-environmental modelling platforms assume a fixed crop mask, i.e., they tend to ignore a basic form of adaptation: under

\footnotetext{
* Corresponding author. Tel.: +39 02 50316515; fax: +39 0250316575 .

E-mail address: roberto.confalonieri@unimi.it (R. Confalonieri).
}

changed conditions, farmers will switch, where possible, to cultivars and crop species that become more suitable under changed conditions.

Importantly from a modelling platform perspective, the few crop suitability tools that are currently available are platformspecific and cannot be easily re-used in custom-developed applications. This implies that users interested in suitability modelling solutions must currently also adopt pre-determined crop growth platforms. The Suitability software proposed here allows to overcome this barrier. It was developed for maximum flexibility of use, as a framework-independent .NET 3.5 component, implementing a library of approaches for evaluating crop suitability to environment.

\section{The software component}

\subsection{Implemented approaches}

The approaches implemented in the component are taken from the literature, with specific additional options implemented for increased flexibility of use (Table 1 ).

Two main categories of approaches are available in the software component, providing for single- and multi-cell criteria. Single-cell criteria include (i) the FAO Ecocrop approach, based on cropspecific response functions to temperature and rainfall calculated on a monthly basis (Ecocrop, 2012); (ii) the Less Favoured Areas (LFA) approach, based on thresholds on climatic data, a simplified 
Table 1

Factors, inputs and description of suitability criteria implemented in the Suitability component.

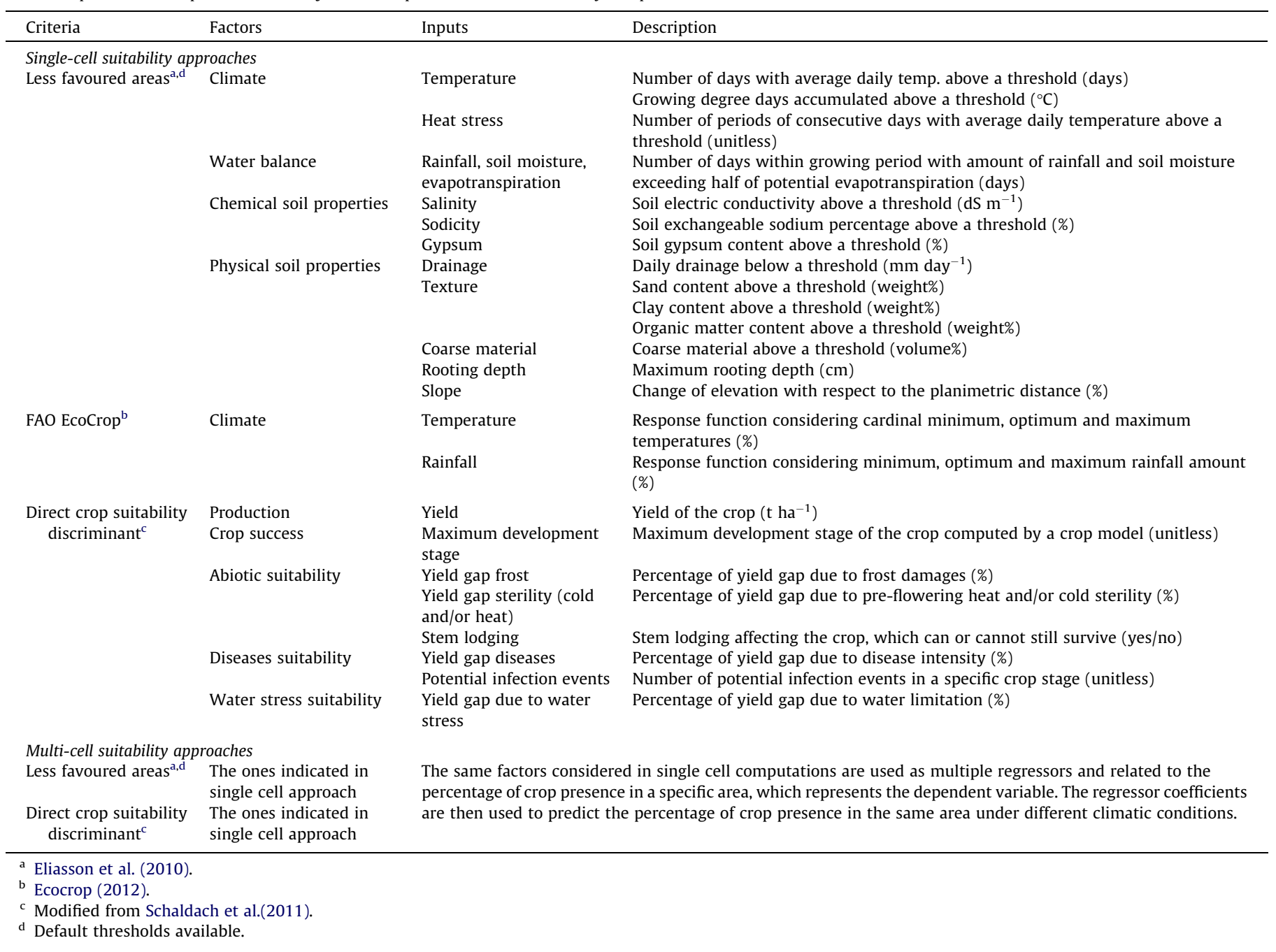

water balance, and soil physical and chemical properties (Eliasson et al., 2010); (iii) the Direct Crop Suitability Discriminant (DCSD), based on data simulated by a dynamic cropping system model (e.g., Schaldach et al., 2011).

Multi-cell approaches are based on the use of multiple regressions, used to relate current crop geographic distribution in a given area - constituted by single spatial units (i.e., the grid cells) - to climate, soil or simulated crop data (e.g., Moriondo et al., 2010). The derived regression models are then used to predict the percentage of crop presence in each cell under, e.g., a different climate. In this case, the component implements two regression-based methods, each using as regressors the information used by two of the single-cell approaches described above (LFA and DCSD). Specific options are available in case of data unavailability, e.g., lack of soil physical or chemical properties.

In addition, a District criterion can be coupled as an option to either single- or multi-cell estimations. This criterion allows to mimic farmers' behaviour in tending to aggregate crops in production districts (Kurosaki, 2003), and is based on the following rules: if the percentage of neighbouring cells where the same crop is computed as present by the suitability model is higher than a user's specified threshold (high threshold), the district criterion increases the percentage of crop presence of the cell by a user specified percentage value; the opposite is done in case of percentage presence in the cell lower than another user's specified threshold (low threshold); otherwise (percentage value between high and low thresholds), it does not modify the percentage of crop presence for the cell.

Detailed description of all the suitability criteria implemented is provided in the component help file.

Finally, the Suitability component can be run by directly selecting a specific approach, or alternatively by an automatic procedure, whereby the software selects the most appropriate suitability method based on the information available. An example flow chart describing the implementation of the Less Favoured Areas criterion is presented in Fig. 1, showing the possibility to compute partial suitability outputs and to activate/deactivate categories of biophysical factors according to user needs or inputs availability.

\subsection{Software design}

The Suitability component implements the Strategy pattern (Gamma et al., 1995), with each strategy encapsulating the algorithm, the parameters' ontology, and pre- and post-conditions tests, according to the design-by-contract approach (Meyer, 1997). The strategy diagram of the Suitability component is shown in Fig. 2.

The software design, which allows for extending data-types, as well as adding new suitability criteria without the need of recompilation (Donatelli and Rizzoli, 2008), promotes reusability by limiting dependencies (limited to Extreme.Numerics and CRA.Core.Preconditions in this case) and by providing two 


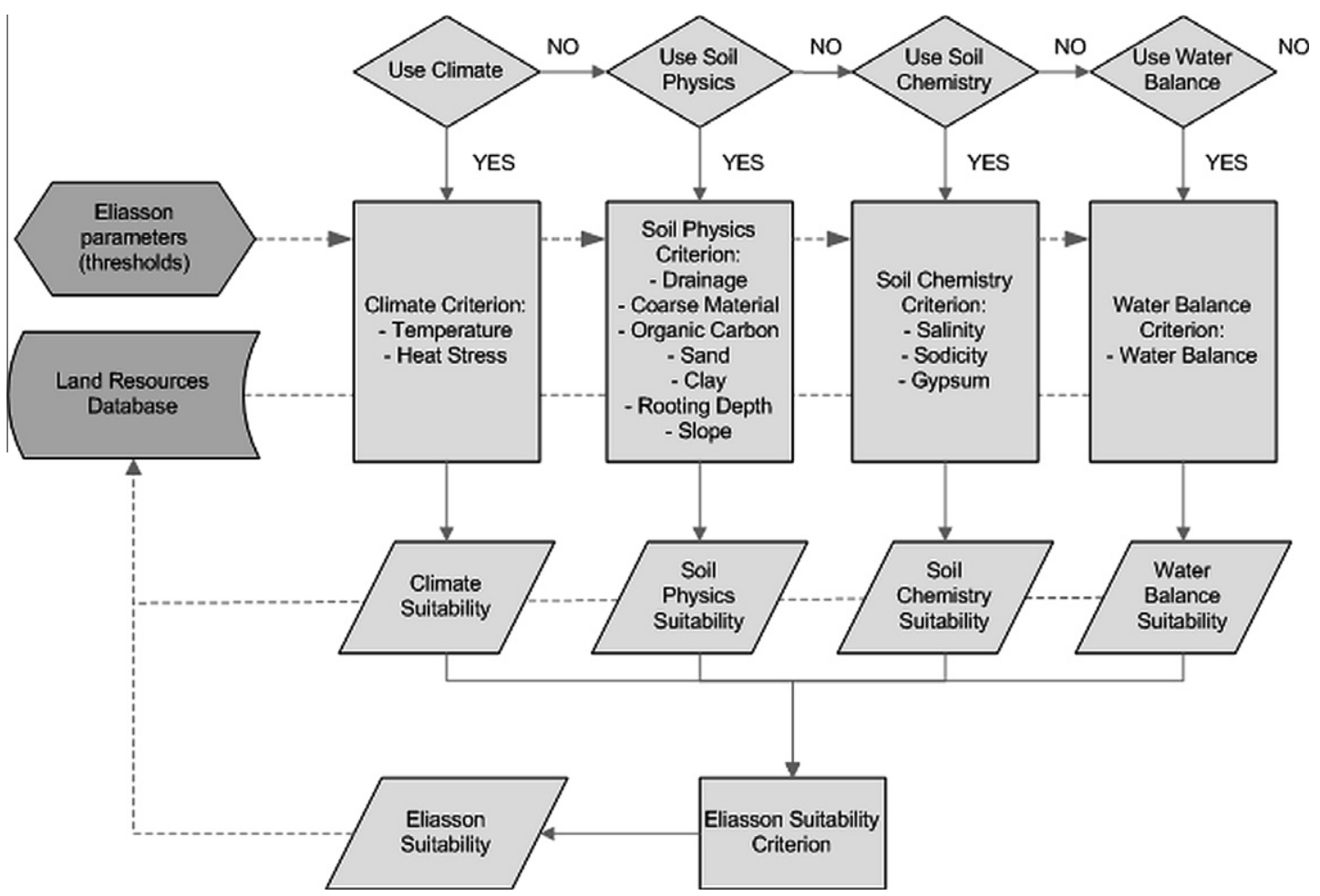

Fig. 1. Flow chart describing the implementation of the less favoured areas criterion in the Suitability component.

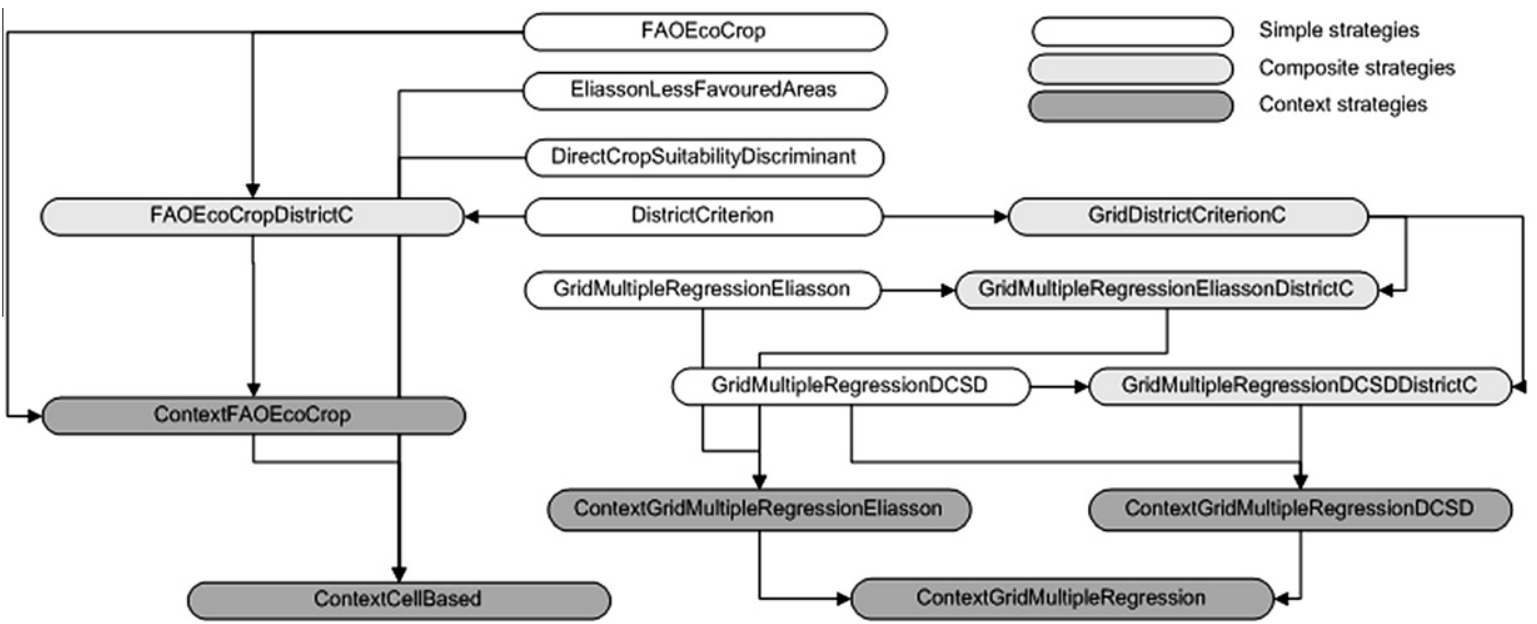

Fig. 2. Strategy diagram of the Suitability component.

semantically rich, public interfaces for single- and multi-cell estimations, as shown in Fig. 3 (IStrategySuitability and IstrategySuitabilityGrid, respectively).

It also allows third parties to add additional suitability approaches, by specifying new strategies and extending the Domain Classes (data-types, used as either input or input-output parameters in the interface of the component and implementing attributes of each variable); as well as to easily compare different suitability approaches. Further details about the software design are provided by Donatelli et al. (2009).

Suitability is distributed in a Software Development Kit (SDK) including hypertext files documenting its code, the implemented approaches, software design and use, C\# source codes of sample clients for single- and multi-cell applications, and Visual Studio sample projects for extending the component in the .NET languages C\#, VB.NET and $\mathrm{C}++$ (www.robertoconfalonieri.it/UNIMI.Suitability_SDK.zip).
Finally, Suitability interfaces, domain classes and strategies, can be inspected via the external application named Model Component Explorer (http://agsys.cra-cin.it/Tools/MCE/help/) (Fig. 4).

\section{A case study}

Wheat suitability to climate conditions in Morocco was evaluated using the FAO EcoCrop criterion. This approach is based on response functions calculated by relating monthly temperatures and cumulated rainfall to crop specific parameters during the growing period. The overall wheat suitability for a grid cell is equal to the minimum between the suitability scores calculated for temperature and rainfall. The study was carried out considering the period November-May and using weather data averaged for the decade 2001-2010. Weather data were derived from the ECMWF 


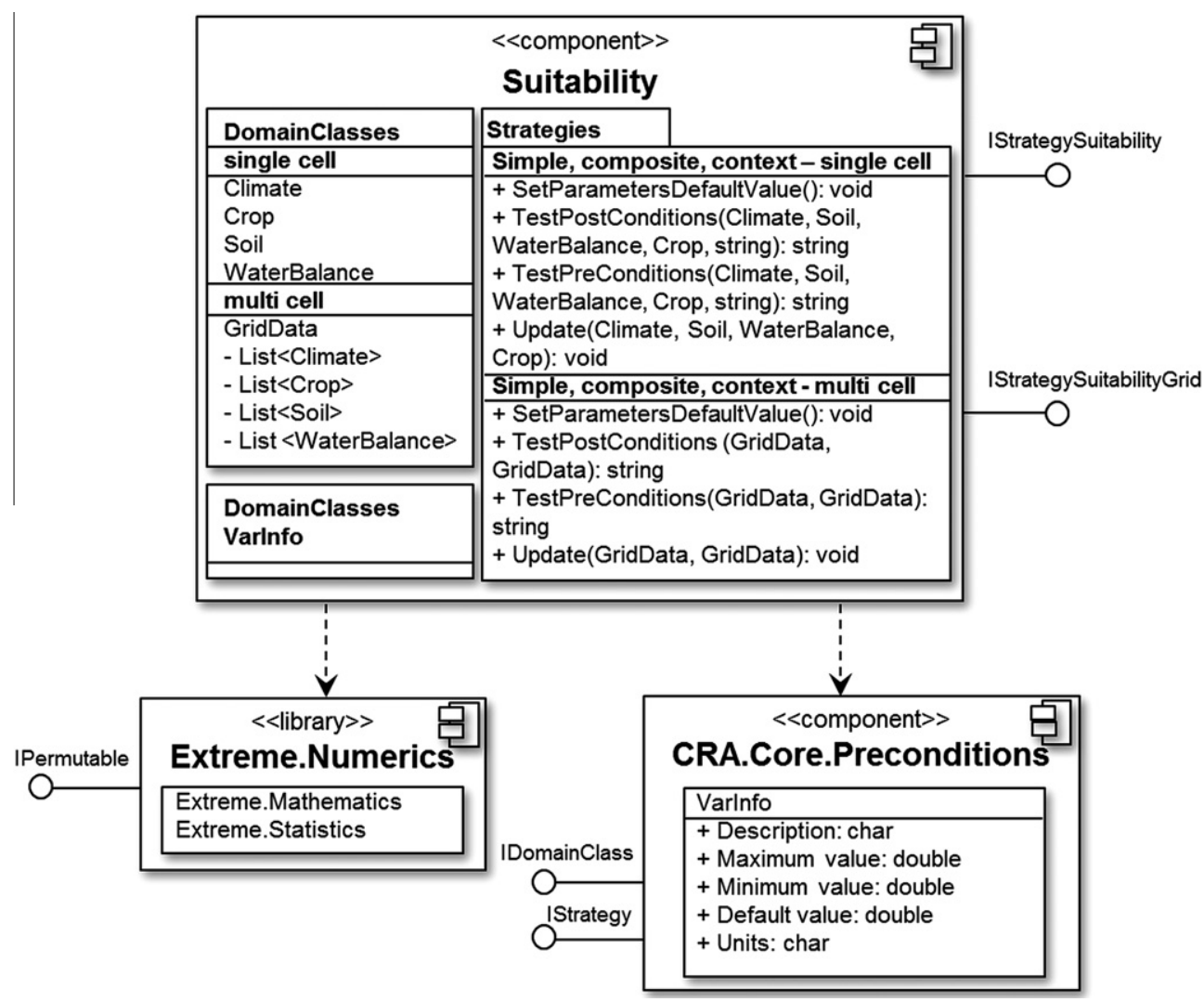

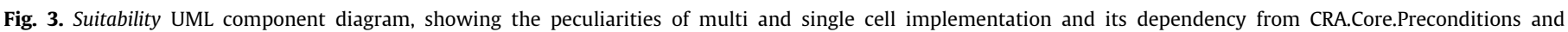
Extreme.Numerics components.

(European Centre for Medium-Range Weather Forecasts) ERAInterim reanalysis database (http://www.ecmwf.int/research/era/ do/get/era-interim). The presence of zones with different climates (e.g., Mediterranean and Atlantic coasts, Atlas mountain range, Sahara desert) makes the study area eligible for a suitability analysis, with wheat exploring a variety of agro-environmental conditions. Results of the FAO EcoCrop criterion were compared with information on percentage wheat presence at $25 \times 25 \mathrm{~km}$ spatial resolution coming from the MARS database (European Communities, 2008), assuming the percentage wheat presence in the cells as a suitability indicator.

The criterion pointed out errors of omission and commission in 68 and eight out of the 846 Moroccan grid cells, respectively (Fig. 5a). Errors of omission (i.e., estimation of non-suitability for cells where wheat is cultivated) were related only to rainfall or thermal conditions in 27 and 37 cases, respectively. In four cells wheat resulted non suitable for both temperature and rainfall. Most of the cells where errors of omission occurred (48 out of 68 ) present a percentage wheat cover lower than $5 \%$, thus allowing to consider the error as negligible in those cases. Moreover, omission errors due to cumulated rainfall (negligible or not) are distributed alongside the Atlas mountain range, where watercourses (not accounted for in the EcoCrop criterion) could support irrigation more than rainfall (Kharrou et al., 2011). Errors of commission (i.e., estimation of suitability for cells where wheat is not cultivated) occurred in less cases and were confined in a narrow area in the north-east of the country (Fig. 5a). Probably, in these cells more specific indicators (e.g., indicators related to agronomic or socio-economic conditions) are needed, in addition to temperature and rainfall, to correctly detect the non-suitability for wheat.

The criterion exactly matched the MARS wheat mask in the desert zone (Fig. 5b). Moreover, the criterion indicated the suitability of wheat in the cultivated areas on the north of the Atlas mountain range, although producing a similar number of under- and overestimations, with the latter being more relevant (coefficient of residual mass $=-0.21$ ). The mean absolute error, considering the large number of grid cells, was however small (0.05).

These results highlighted a good compromise between the goodness of fit of the criterion and its parsimony in terms of input requirement, making it proper for large-area suitability studies.

\section{Discussion and conclusions}

The availability of operational tools for evaluating crop suitability is key to better forecast geographic crop distributions and consequently production levels. This is particularly important for improving climate change crop assessment studies, as it allows to include improved information, moving beyond the current use of fixed crop masks. This is in fact related to a form of adaptation that is often not considered in simulation studies under climate change scenarios: the switch to crops becoming more suitable under changing conditions. The Suitability component provides a library of approaches for computing crop suitability, providing an easily applicable methodology for: (i) the comparison among different suitability criteria at sites, and (ii) consistent extension for large area simulations. The software design of the component allows for the independent inclusion of additional criteria by third parties and its reuse in new software applications. The software package provided is supported by an extensive documentation of the algorithms implemented or of the code, as well as by sample applications showing how to extend and link the Suitability component to different input data sources. 


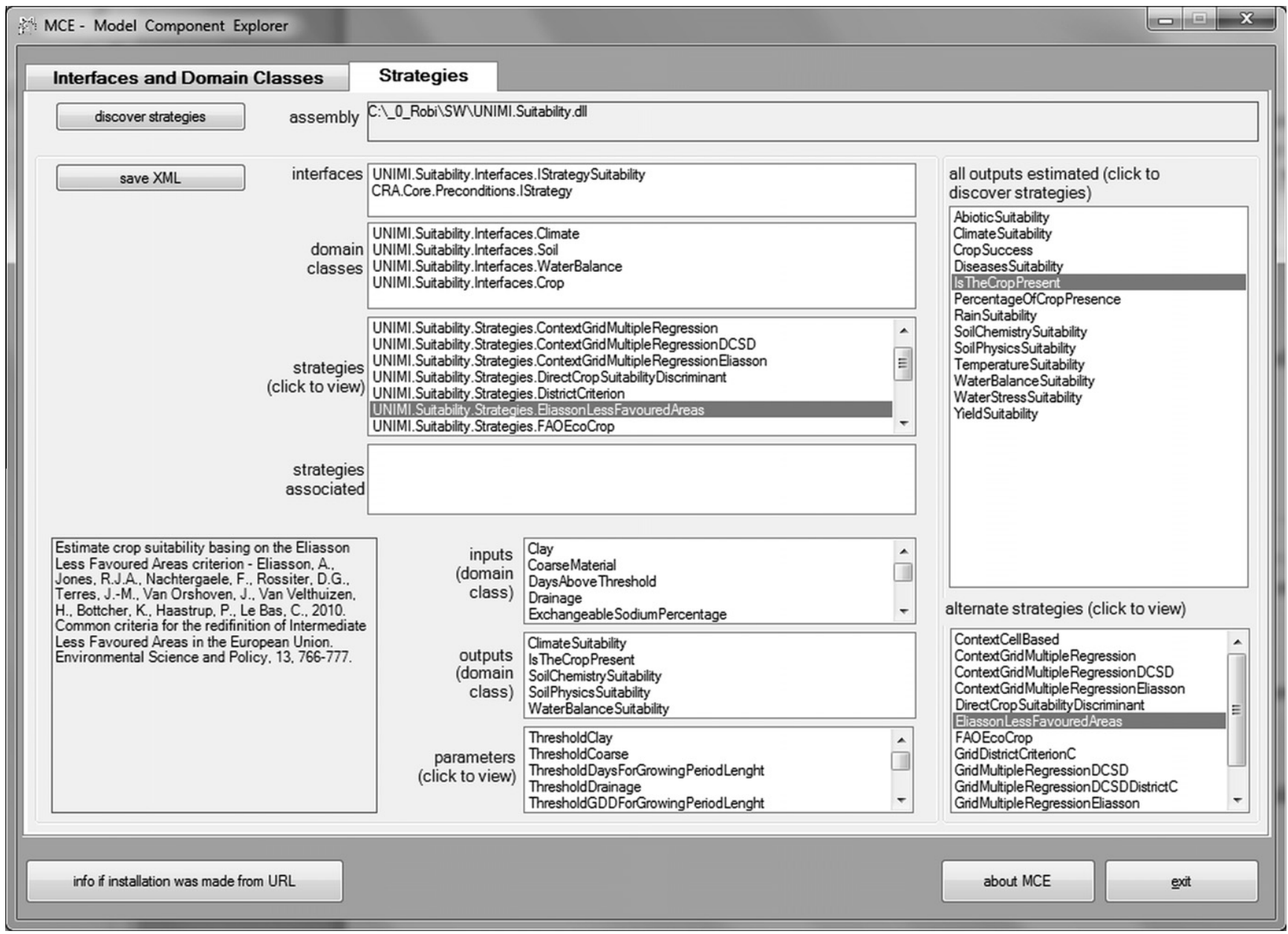

Fig. 4. Suitability inspected with the Model Component Explorer (http://agsys.cra-cin.it/Tools/MCE/help/).
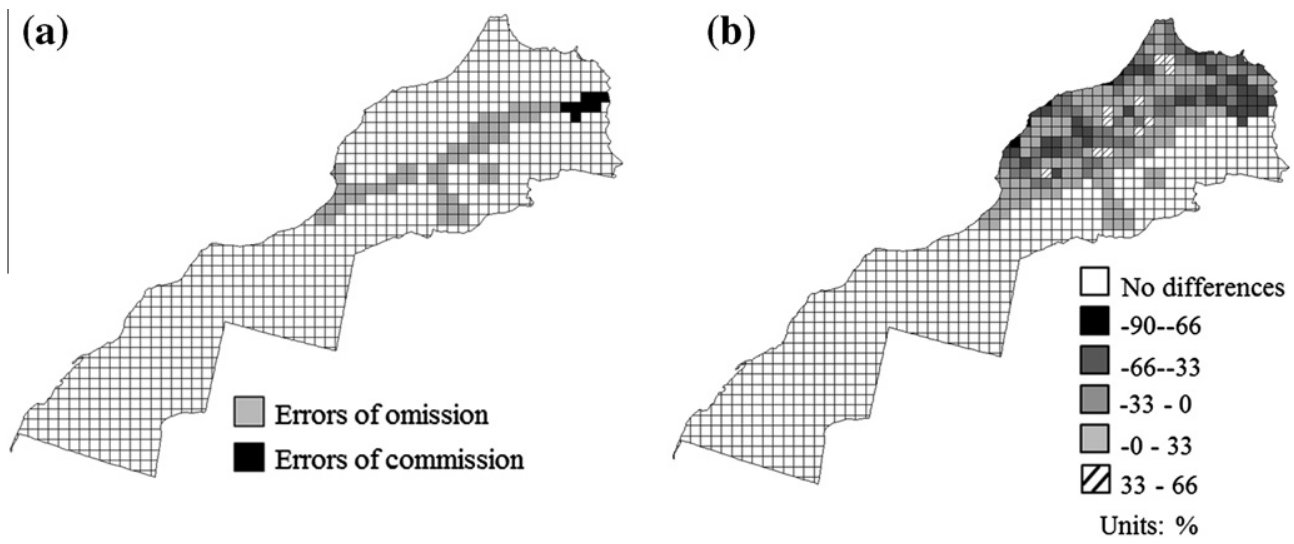

Fig. 5. Application of the FAO EcoCrop suitability criterion to wheat in Morocco. (a) Spatial distribution of errors of omission and commission; (b) percentage differences between estimated and actual (MARS wheat mask) suitability values. See text for details.

\section{Acknowledgments}

The Suitability component was developed within the World Bank's Climate Change Impact on Agriculture in Latin America and the Caribbean regional project, made possible by the generous contribution of the Spanish Ministry of Economy and Finance, through the Spanish Fund for Latin America (SFLAC). The activities related to the case studies have been partially funded under the EU FP7 collaborative project, Grant Agreement No. 270351, Crop monitoring as an E-agriculture tool in developing countries (E-Agri).

\section{References}

Ceballos-Silva, A., López-Blanco, J., 2003. Delineation of suitable areas for crops using a multi-criteria evaluation approach and land use/cover mapping: a case study in Central Mexico. Agr. Syst. 77, 117-136.

Donatelli, M., Rizzoli, A.E., 2008. A design for framework-independent mode components of biophysical systems. In: Proceedings of the International Congress on Environmental Modelling and Software (iEMSs 08), vol. 2. Barcelona, Spain, pp. 727-734.

Donatelli, M., Bellocchi, G., Habyarimana, E. Confalonieri, R, Micale, F., 2009. An extensible model library for generating wind speed data. Comput. Electron. Agric. 69, 165-170. 
Ecocrop, 2012. Ecocrop database. Food and Agriculture Organization of the United Nations (FAO). <http://ecocrop.fao.org/ecocrop/srv/en/home> (accessed 26.03.12).

Eliasson, A., Jones, R.J.A., Nachtergaele, F., Rossiter, D.G., Terres, J.M., Van Orshoven, J., Van Velthuizen, H., Bottcher, K., Haastrup, P., Le Bas, C., 2010. Common criteria for the redefinition of intermediate less favoured areas in the European Union. Environ. Sci. Policy 13, 766-777.

European Communities, 2008. CGMS Version 9.2: User Manual and Technical Documentation. JRC Scientific and Technical Reports. Joint Research Centre, European Commission. Office for Official Publications of the European Communities. Luxembourg.

Gamma, E., Helm, R., Johnson, R., Vlissides, J., 1995. Design Patterns: Elements of Reusable Object-Oriented Software. Addison Wesley.

Hood, A., Cechet, B., Hossain, H., Sheffield, K., 2006. Options for Victorian agriculture in a "new" climate: pilot study linking climate change and land suitability modelling. Environ. Model. Softw. 21, 1280-1289.

Jarvis, A., Lane, A., Hijmans, R.J., 2008. The effect of climate change on crop wild relatives. Agr. Ecosyst. Environ. 126, 13-23.
Jing-Song, S., Guang-Sheng, Z., Xing-Hua, S., 2012. Climatic suitability of the distribution of the winter wheat cultivation zone in China. Eur. J. Agron. 43, 7786.

Kharrou, H., Er-Raki, S., Chehbouni, A., Duchemin, B., Simonneaux, V., LePage, M., Ouzine, L., Jarlan, L., 2011. Water use efficiency and yield of winter wheat under different irrigation regimes in a semi-arid region. Agric. Sci. 2, 273-282.

Kurosaki, T., 2003. Specialization and diversification in agricultural transformation: the case of West Punjab, 1903-92. Am. J. Agr. Econ. 85, 372-386.

Meyer, B., 1997. Object-Oriented Software Construction, second ed. Prentice Hall, Upper Saddle River, NJ, USA.

Moriondo, M., Bindi, M., Fagarazzi, C., Ferrise, R., Trombi, G., 2010. Framework for high-resolution climate change impact assessment on grapevines at a regional scale. Reg. Environ. Change. http://dx.doi.org/10.1007/s10113-010-0171-z.

Schaldach, R., Alcamo, J., Koch, J., Kölking, C., Lapola, D.M., Schüngel, J., Priess, J.A., 2011. An integrated approach to modelling land use change on continental and global scales. Environ. Model. Softw. 26, 1041-1051.

Woodward, F.I., 1987. Climate and Plant Distribution. Cambridge University Press, London. 